\title{
Sobre la reprobación parlamentaria de expresidentes y diputados en activo
}

\author{
Victor 7. Vázquez Alonso
}

De entre las muchas consecuencias derivadas de la causa penal de los ERE, una de ellas ha sido la de abrir en el seno del Parlamento andaluz una discusión jurídica acerca de los límites de una institución de control parlamentario como son las proposiciones no de ley. En concreto, el origen de esta discusión se encuentra en la "Proposición no de ley relativa a la reprobación de los Gobiernos socialistas relacionados con la utilización ilegal de los fondos públicos enjuiciados en la causa judicial de los ERE y con la obstaculización de su recuperación posterior"1, que fue presentada por el Grupo Parlamentario de Adelante Andalucía, y cuyo tenor literal es el siguiente:

1. El Parlamento de Andalucía reprueba a los gobiernos socialistas que idearon un sistema reputado ilegal de concesión de dinero público y lo aplicaron, presididos por los señores Chaves y Griñán.

2. El Parlamento de Andalucía reprueba a Susana Díaz Pacheco y al Ejecutivo presidido por ella, que decidió abandonar la causa de la pieza política de los ERE, decisión que dificulta, dilata y limita la recuperación de los fondos públicos utilizados al margen de la ley.

3. El Parlamento de Andalucía insta al Consejo de Gobierno a adoptar cuantas medidas sean necesarias para garantizar procedimientos limpios y transparentes en la adjudicación de ayudas públicas y la absoluta imparcialidad de los criterios para su otorgación y cálculo de sus cuantías. Para ello, deberá presentar a este Parlamento, en un plazo no superior a tres meses, un informe detallado de los cambios operados en cumplimiento de los informes de la Cámara de Cuentas emitidos a tales efectos, y de todos aquellos cambios adoptados o previstos para mejorar los procedimientos ilegales y opacos identificados en estos años de corrupción, que garanticen la salvaguarda del interés general y el uso debido de los recursos públicos.

4. El Parlamento de Andalucía insta al Consejo de Gobierno, para que a su vez inste al Gobierno central, a impulsar las reformas legislativas necesarias para garantizar la responsabilidad subsidiaria de los partidos políticos cuyos miembros hayan sido condenados en firme por delitos relacionados con la

11-19/PNLP-000115 
corrupción, en los casos en los que el partido político en cuestión se haya beneficiado.

El objeto de la controversia tiene que ver, como rápidamente puede intuirse, con las personas que expresamente son mencionadas como destinatarias de la reprobación, y ello en tanto se trata de personalidades que han tenido las máximas responsabilidades en ejecutivos anteriores, pero que no forman parte del gobierno autonómico actual. Al mismo tiempo, se da la circunstancia de que una de las personas aludidas, Susana Díaz, es en la actualidad diputada del Parlamento andaluz, del mismo modo que los son otros diputados que en su día integraron su gobierno y sobre el cual se pide igualmente un pronunciamiento reprobatorio en su conjunto.

Como es conocido, el uso parlamentario, tanto a nivel nacional como autonómico, ha hecho de las proposiciones no de ley un instrumento que, más allá de su lógica propositiva, sirve hoy como expresión de censura parlamentaria a determinadas políticas de los ejecutivos, y a los responsables de las mismas. A este respecto, tal y como ha señalado reiteradamente la jurisprudencia constitucional, las proposiciones no de ley "se configuran como un instrumento para poner en marcha la función de impulso político y control del Gobierno, pero, también, como una vía adecuada para forzar el debate político y obligar a que los distintos grupos de la Cámara y esta misma tengan que tomar expresa posición sobre un asunto o tema determinado, por lo que, en razón de esta doble naturaleza, las Mesas de las Cámaras, en tanto que órganos de administración y gobierno interior, han de limitar sus facultades de calificación y admisión a trámite al exclusivo examen de los requisitos reglamentariamente establecidos".

La cuestión que aquí se planteaba, en este sentido, es doble. Por un lado, si dicha figura de control parlamentario puede ser utilizada para censurar no a quienes hoy desempeñan tareas de gobierno sino a quienes lo han hecho en el pasado. Y, en segundo lugar, se plantea también la cuestión de si es posible, desde la propia lógica del control parlamentario, que dicha reprobación pueda tener como objetivo no a quien desempeña funciones ejecutivas, sino a quien en ese momento, como Susana Díaz forma parte de la oposición parlamentaria, es decir, frente a quien posee la condición de diputado.

Estas incertezas, como era lógico, dieron lugar a la solicitud por parte de la Mesa de un informe jurídico que delimitara los perfiles básicos y el alcance de las proposiciones no de ley. Solicitud que tuvo como respuesta un extenso informe de uno de los letrados de la Cámara, Manuel Carrasco Durán, en el que se hace un loable esfuerzo por encuadrar la respuesta, a la postre contraria a la viabilidad de la propuesta, a partir de los presupuestos teóricos fundamentales del control parlamen- 
tario $^{2}$. En este sentido, intentaré resumir, porque vale la pena, cuál fue el planteamiento ofrecido por los servicios jurídicos del Parlamento, como veremos, finalmente rechazado por la Mesa.

Para los servicios jurídicos, la cuestión relativa a la reprobación de ex Presidentes autonómicos exige plantearse de forma previa la propia pregunta de si es viable el uso reprobatorio de la proposición no de ley contra los jefes del ejecutivo, durante su mandato. La respuesta a esta pregunta sería, en opinión del letrado, inequívocamente negativa. El argumento principal sobre el que se construye esta tesis parte de la propia configuración estatutaria del régimen de responsabilidad del Presidente autonómico, es decir, de la moción de censura. A este respecto, y como es por todos conocido, el estatuto andaluz regula esta institución en términos miméticos a como se hace en la Constitución española con respecto al Congreso estatal, es decir: se trata de un moción de naturaleza constructiva que en el caso de prosperar, por obtener la mayoría absoluta de la Cámara, tiene como efecto jurídico la dimisión del Presidente objeto de la misma y la consecuente investidura del candidato (art. 126 EAA) ${ }^{3}$. En atención a esto, se sostiene en el informe que admitir un instrumento de reprobación parlamentaria del jefe del ejecutivo autonómico, a margen del procedimiento del artículo 126 constituiría una suerte de "fraude de estatuto", en la medida que se estarían obviando las normas y los efectos con los que la norma fundamental de la comunidad autónoma ha querido regular la censura parlamentaria del jefe del ejecutivo.

Distinto será, a este respecto, la respuesta a la cuestión relativa a una eventual reprobación parlamentaria a cualquiera de los restantes miembros del ejecutivo autonómico. La radical diferencia de partida es, en este sentido, que el estatuto, en la línea del parlamentarismo español derivado de la Constitución del 78, y al contrario que su antecedente republicano, no prevé la posibilidad de individualizar la moción de censura parlamentaria y sus efectos jurídicos, en alguno de los miembros del eje-

2 INFORME N. ${ }^{\circ} 245$ de fecha 3 de diciembre de 2019, acerca de la Proposición no de ley en Pleno 11-19/PNLP-000115, relativa a reprobación de los gobiernos socialistas relacionados con la utilización ilegal de los fondos públicos enjuiciados en la causa judicial de los ERE, y con la obstaculización de su recuperación posterior.

3 1. El Parlamento puede exigir la responsabilidad política del Consejo de Gobierno mediante la adopción por mayoría absoluta de la moción de censura. Ésta habrá de ser propuesta, al menos, por una cuarta parte de los parlamentarios y habrá de incluir un candidato o candidata a la Presidencia de la Junta. La moción de censura no podrá ser votada hasta que transcurran cinco días desde su presentación. Si la moción de censura no fuese aprobada por el Parlamento, sus signatarios no podrán presentar otra durante el mismo período de sesiones.

2. Si el Parlamento adoptara una moción de censura, el Presidente de la Junta presentará su dimisión ante el Parlamento y el candidato incluido en aquélla se entenderá investido de la confianza de la Cámara. El Rey le nombrará Presidente de la Junta. 
cutivo $^{4}$. Es por este motivo que, en la práctica, distintas herramientas de control e impulso parlamentario a la acción de gobierno, y en este caso, las propias proposiciones no de ley, han servido para encauzar un mecanismo de control y exigencia individualizada de responsabilidad política frente a los miembros del ejecutivo. Se trata obviamente de escenificaciones de responsabilidad que no poseen otros efectos que los estrictamente políticos, dado que, como es sabido, en este último término lo miembros del ejecutivo sólo responden frente a su Presidente.

Sobre estos presupuestos, y proyectados sobre el caso que nos compete, los servicios jurídicos concluyeron que no es viable tampoco, en el marco estatutario andaluz, una reprobación parlamentaria que tenga como objeto a los ex presidentes del ejecutivo. El argumento de cierre de esta tesis es que carecería de toda lógica que aquello que no se podía hacer durante el mandato de los mismos, devenga jurídicamente viable cuando estos ya han abandonado dicha responsabilidad. A este respecto, creo que puede decirse que la postura mantenida por los servicios jurídicos de la Cámara vela por mantener un mínimo de racionalidad procedimental en el uso de los instrumentos de control e impulso parlamentario de la acción de gobierno. En definitiva, se intenta, en aras de ese parlamentarismo racionalizado, poner coto a la inevitable ductilidad de los instrumentos puestos a favor de la cámara para llevar a cabo estas funciones de control. Se podría objetar, a este respecto, que en ese afán se ve menoscabada la propia autonomía del órgano para interpretar sus funciones y repensar las potencialidades de sus instrumentos de acción.

A este respecto, otro argumento contra la tesis sostenida por los servicios jurídicos podría ser que no son asimilables las reprobaciones que puedan debatirse contra el jefe del ejecutivo a través de un instrumento como la proposición no de ley, al propio debate al que da lugar el uso de la moción de censura. Dicho de otra forma, que podría escalonarse como un instrumento diferenciado de exigencia de responsabilidad al presidente del ejecutivo, mociones o reprobaciones donde resulta evidente que la cámara no quiere cuestionar la confianza parlamentaria depositada de forma general en la investidura, pero sí censurar, por algún motivo, aspectos, decisiones o derivas de la acción de gobierno.

4 Existe, en este sentido, un precedente relevante sobre esta cuestión. Se trata de la Proposición no de Ley en Pleno 4-94/PNLP-05325, relativa a reprobación y cese de la Consejera de Economía y Hacienda. En este caso, el Letrado Mayor llegó a la conclusión de que nada en el Estatuto de autonomía se oponía a que existan mociones de reprobación individuales de los Consejeros sin que estas obviamente impliquen el cese de los mismo en caso de prosperar. Ahora bien, como en esta ocasión, también entonces el Letrado Mayor, mostró su disconformidad a la tramitación de mociones contra el Presidente de la Junta o el Consejo de Gobierno, y ello en tanto se estaría vaciando de contenido el marco estatutario relativo a la responsabilidad política del ejecutivo, y también las propias normas del reglamento parlamentario (Art. 133-137) que regulan estos procedimientos. 
En cualquier caso, como decíamos, lo que en último término han premiado los servicios jurídicos es una interpretación favorable a optimizar la racionalización de la vida parlamentaria, sobre la base de las que no dejan de ser sus normas, digamos estructurales, de funcionamiento.

A este respecto, muchas menos dudas suscita la respuesta ofrecida al segundo de los interrogantes que planteaba la propuesta reprobación sometida a consideración por el grupo parlamentario de Adelante Andalucía, y que es la de si es o no posible la reprobación de quien en ese momento disfruta de la condición de diputado. Como puede intuirse de aceptarse dicha posibilidad se estaría de alguna forma afectando la dialéctica lógica que subyace en las instituciones de control parlamentario, donde existe un fiscalización, digamos, de cuño ascendente, desde la cámara hacia el ejecutivo. Pero más allá de esto, y como con acierto se advierte en la propia respuesta de los servicios jurídicos; de admitir reprobaciones contra parlamentarios se estaría abriendo la puerta a una dinámica tan perniciosa como la de que las mayorías parlamentarias usen los instrumentos propios del control gubernamental para censurar a los grupos parlamentarios minoritarios. A este respecto, la mera posibilidad de que se pueda producir esa perversión creo que justifica sobradamente la postura refractaria a esos planteamientos.

En cualquier caso, estas razones no fueron atendidas por la Mesa del Parlamento andaluz, que finalmente decidió dar el sí a la tramitación de la proposición no de ley promovida por el grupo parlamentario Adelante Andalucía, si bien, en último momento, dicha proposición no ha llegado a debatirse dado que apelando a "cuestiones técnicas" dicho grupo ha decidido finalmente retirar la misma.

Dicha retirada ha evitado lo que muy probablemente hubiera derivado en un pronunciamiento del Tribunal Constitucional acerca del uso y los contornos que puede adquirir una figura de impulso parlamentario, como la proposición no de ley, y, en concreto, hasta qué punto a través de la misma pueden vehicularse acciones reprobatorias contra miembros del ejecutivo e incluso contra parlamentarios.

Obviamente, cualquier interpretación restrictiva con respecto al uso que se quiera dar en la práctica parlamentaria a estos instrumentos se enfrenta a objeciones tanto desde la perspectiva de la autonomía parlamentaria como de la propia eficacia de los derechos del artículo 23 de la Constitución, del cual las proposiciones no de ley no dejarían en último término de ser expresión ${ }^{5}$. A este respecto, como ha reiterado la jurisprudencia constitucional, las mesas de las cámaras no pueden asumir" bajo un

5 A este respecto el Tribunal Constitucional a reiterado que el art. 23.2 CE no sólo garantiza el acceso igualitario a las funciones y cargos públicos, sino también que los que hayan accedido a los mismos se mantengan en ellos y los desempeñen de conformidad con lo que la ley disponga (véase, por todas, 1/2015, de 19 de enero, FJ 3). 
CRÓNICI PHRLMIEMTTRII

pretendido juicio técnico, una decisión política que sólo al Pleno o a las Comisiones de las Cámaras corresponde", ya que "desde la óptica de la representación democrática, estarían obstaculizando la posibilidad de que se celebre un debate público entre las distintas fuerzas políticas con representación parlamentaria, cuyos efectos representativos ante los electores se cumplen con su mera existencia, al margen, claro está, de que la iniciativa, en su caso, prospere" (SSTC 40/2003, de 27 de febrero, FJ 7, 78/2006, de 13 de marzo, FJ 3, y 158/2014, FJ 4).

En cualquier caso, y en sintonía con los argumentos por el letrado Manuel Carrasco, autor del informe comentado, la conservación de los principios sobre los que descansan las relaciones gobierno-parlamento, y la propia racionabilidad de la vida parlamentaria, son argumentos especialmente valiosos a la hora de justificar restricciones a ciertas lecturas de los instrumentos de control parlamentario que, independientemente de su bien-intencionalidad, pueden pervertir presupuestos innegociables del parlamentarismo. 